Cómo citar este trabajo: Jover Báez, J. (2019). Geografía comercial de los centros históricos: entre la gentifricación y la patrimonialización. El caso de Sevilla. Boletín de la Asociación de Geógrafos Españoles, 82, 2788, 1-33. http://dx.doi.org/10.21138/bage.2788

\title{
Geografía comercial de los centros históricos: entre la gentrificación y la patrimonialización. El caso de Sevilla
}

\author{
Geography of shopping in historic districts: between gentrification \\ and heritagezation. A study case in Seville
}

\author{
Jaime Jover Báez \\ jaimejb@euosuna.org \\ Escuela Universitaria de Osuna \\ Universidad de Sevilla (España)
}

\begin{abstract}
Resumen
El estudio de la geografía comercial de las ciudades es de elevado interés, especialmente cuando la urbanización y procesos como la gentrificación han adquirido un carácter planetario. La literatura sobre la ciudad capitalista se ha centrado, por lo general, en la transformación urbana, la dinámica del mercado de la vivienda o el desplazamiento de poblaciones autóctonas en relación a las políticas neoliberales a diferentes escalas. Sin embargo, en los últimos años y asociado a todo esto ha ganado peso el análisis del tejido comercial, en lo que este trabajo profundiza en un contexto urbano patrimonial. Así, se abordan los cambios en la geografía comercial del centro histórico de Sevilla, planteando las hipótesis de la gentrificación y la patrimonialización a través de la evolución paralela de los establecimientos comerciales tradicionales y las franquicias y grandes firmas en el último cuarto de siglo. Para ello, el trabajo combina análisis cualitativos y cuantitativos sobre las diferentes fuentes bibliográficas y estadísticas existentes.
\end{abstract}

Palabras clave: geografía comercial; centro histórico; gentrificación; patrimonialización; Sevilla. 


\begin{abstract}
As urbanization and gentrification have become planetary processes, research on commercial geographies has progressively gained importance. In studying the capitalist city, literature has generally focused on urban transformations, the housing market dynamics or indigenous population displacement in relation to neoliberal politics and policies at different scales. However, changes on the commercial fabric have also attracted scholarly attention in recent years. This paper delves into the geography of shopping in urban heritage contexts, specifically through a study case in Seville's historic district. My hypothesis is two parallel processes have unfolded and fed back: gentrification and heritagezation, what I explore by analyzing the evolution of traditional retail shops, franchises and large firms in the last two decades. To do so, the article combines quantitative and qualitative analyses on diverse bibliographic and statistical sources on the topic.
\end{abstract}

Key words: geography of shopping; historic district; gentrification; heritagization; Seville.

\title{
1 Introducción
}

\subsection{Estado de la cuestión e hipótesis}

Eran unas covachas abiertas en el muro de la iglesia, a veces defendidas por una pequeña cristalera, otras de par en par sobre la plaza el postigo, que sólo a la noche se cerraba. Dentro, tras el mostrador, silencioso y solitario, aparecía un viejo pulcro, vestido de negro, que lleno de atención pesaba algo en una minúscula balanza, o una mujer de blancura lunar, el pelo levantado en alto rodete y sobre él una peina, abanicándose lentamente. ¿Qué vendían aquellos mercaderes? [...] En esas tiendecillas de la plaza del Pan cada uno de los objetos expuestos eran aún cosa única, y por eso preciosa, trabajada con cariño, a veces en la trastienda misma, conforme a la tradición transmitida de generación en generación, del maestro al aprendiz, y expresaba o pretendía expresar de modo ingenuo algo singular y delicado. Su atmósfera soñolienta aun parecía iluminarse a veces con el fulgor de los metales, y un aroma de sándalo o ámbar flotar en ellas vagamente como un dejo rezagado. (Cernuda, 1942, p. 97-98).

Luis Cernuda dedica estas palabras a Sevilla desde el exilio. Se trata de un extracto de "las tiendas", epígrafe de Ocnos, texto en prosa que el poeta escribió entre Londres y Glasgow a principios de los años cuarenta del pasado siglo. Para entonces, su ciudad natal comenzaba a ser un recuerdo lejano, y seguramente habría tomado conciencia de que así sería el resto de su vida tras el golpe de Estado y la victoria del bando sublevado en la guerra, cerrando la puerta a una España democrática durante décadas. En Ocnos, Luis Cernuda escribe, sin nombrarla, sobre Sevilla, y realiza muy pocas referencias a sitios concretos. Las tiendecillas de la plaza del Pan son 
una de esas excepciones, seguramente por su particularidad y el ambiente que allí se respiraba, que el poeta evoca con multitud de detalles. La plaza del Pan, hoy renombrada como de Jesús de la Pasión, es uno de los espacios comerciales emblemáticos de Sevilla. En la trasera de la iglesia del Salvador, la plaza del Pan fue durante siglos parte del zoco de la ciudad andalusí, una función que no perdió tras la conquista castellana. De hecho, Luis de Peraza, que la refiere como plaza de Abajo en el siglo XVI, dice que en ella están "las panaderas de Sevilla en su poyo [...] Véndense en esta plaza todo el año peros, y camuesas, cermeñas y peras; todas frutas secas. Así mismo, a su tiempo, cerezas comunes y guindas y mui gruesas cerezas roales, higos verdes y brevas" (Morales Padrón, 1996, p. 105).

Siglos después, el mismo sector sigue siendo un importante espacio comercial de una ciudad cuyo recinto medieval se ha convertido, casi en su totalidad, en el centro histórico. La expansión y transformación urbana de Sevilla a lo largo de los siglos XIX y XX, y en especial durante los últimos cincuenta años, ha supuesto una nueva configuración de la geografía comercial. Desde mediados del siglo XX, se desarrollan nuevos distritos minoristas de relevancia urbana en diferentes barrios, y casi en paralelo aparecen en el centro histórico grandes superficies comerciales, más propias de la ciudad difusa que del modelo compacto mediterráneo, que rompen con la "escala menuda" del centro urbano (Marín de Terán, 1980). Ese mismo modelo de centro comercial se generaliza, junto con nuevos desarrollos urbanos residenciales, desde los años ochenta y con especial intensidad durante los noventa y primeros años del siglo XXI, extendiéndose a la periferia suburbana de Sevilla (Vahí Serrano, 1998). En la actualidad, en el área metropolitana de la capital de Andalucía, en la que residen aproximadamente un millón y medio de habitantes, el comercio todavía está muy concentrado en su primera corona, aunque formando varios espacios comerciales diferentes, próximos a las autovías que actúan como ejes vertebradores del ámbito metropolitano (Vahí Serrano \& Hurtado Rodríguez, 2017). De hecho, los proyectos de nuevos centros comerciales en construcción se sitúan en la orilla de estos ejes, de los que son ejemplo los casos de Palmas Altas o Sevilla Park; o en la periferia urbana, donde multinacionales se han instalado en el Higuerón Sur y en el contestado proyecto de la Torre Pelli (Romero Moragas et al., 2015).

La particularidad de la evolución reciente de la geografía comercial sevillana ha sido el fuerte peso que jamás ha perdido el centro histórico. El estudio de estos espacios urbanos es muy relevante desde al perspectiva patrimonial actual, donde los debates inciden en el diálogo entre territorio y paisaje (Fernández Salinas \& Silva Pérez, 2015; Troitiño Vinuesa \& Troitiño Torralba, 2018). Los centros históricos todavía actúan como lugar de encuentro e intercambio, lo que está en la propia génesis de las ciudades, y se definen por una diversidad de elementos: la arquitectura tradicional (monumental y vernácula), la morfología, los paisajes o la trama urbana. Esta diversidad es igualmente visible en términos socio-demográficos, dando cobijo a lo largo de la historia a todas las clases sociales, y en aspectos funcionales, conjugando usos residenciales, industriales o terciarios, 
como el comercial. Ahora bien, la heterogeneidad que los caracteriza ha ido también acompañada de cierta separación espacial en su interior, por ejemplo la segregación social o la concentración gremial en algunas calles o barrios. Este último proceso lleva con frecuencia en la actualidad a identificar el centro histórico exclusivamente con la zona monumental, por la potencia simbólica de los principales hitos urbanos, relacionados con los poderes fácticos (civiles, religiosos y militares) de la ciudad en perspectiva histórica. A ello también contribuye, en la fase posfordista actual, la explotación turística de tales monumentos. El resultado es que, en no pocas ciudades, se constriñe la idea de centro histórico a una decena de calles que condensan con más fuerza la identidad urbana. Unas calles que, como en el caso de Sevilla, en ocasiones sirven también de centro urbano, donde se localizan un buen número de actividades comerciales. Por ello, no es de extrañar que determinados establecimientos comerciales minoristas de estas zonas, popularmente vistos como tradicionales o clásicos - por la mercancía que venden, que incluso puede ser de elaboración propia; la atención personalizada, el arraigo social o su antigüedad- puedan ser considerados como patrimonio.

Este ha sido el caso del centro urbano de Sevilla en tiempos recientes, donde el cierre de establecimientos comerciales tradicionales ha espoleado el debate. Si bien en algunos casos tal cierre se debe a la jubilación o a la falta de relevo generacional, como la tienda de cerámica Martián (Navarro Antolín, 2018) o la de bisutería Sabina (Geniz, 2018a); en los casos de Uclés (Burgos, 2015), del centenario Bazar Victoria (Correal, 2017) o de la juguetería Cuevas (SánchezMoliní, 2018), las causas fueron bien distintas. Entre ellas se cita con carácter general la crisis económica y la caída de las ventas, y de manera especial el fin de los arrendamientos de renta antigua el 31 de diciembre de 2014, sin olvidar los efectos negativos derivados de la proliferación de nuevos canales comerciales y el aumento de la competencia de las franquicias y grandes firmas. Ambos modelos de negocio, muy comunes en centros comerciales modernos, han seguido estrategias similares de relocalización en centros urbanos en tiempos recientes (Alonso Logroño et al., 2017). Franquicias son las cadenas comerciales que ceden los derechos de explotación de una marca y unos productos asociados a particulares que abren los establecimientos. La titular de la franquicia o enseña no es propietaria o arrendadora del local, solamente se encarga de proveer al franquiciado, con el que se reparte los beneficios. No obstante, las franquicias pueden tener tiendas propias, que normalmente tienen cierto tamaño, se localizan en lugares privilegiados y se las conoce como flagship stores. Las grandes firmas, que hacen referencia a grandes corporaciones nacionales e internacionales, también tienen este tipo de locales. Por grandes firmas se entienden los grandes almacenes, definidos por su tamaño y la variedad de la oferta; la banca y las cadenas comerciales que, si bien no siguen el sistema de franquicia, su modelo de negocio y su comportamiento empresarial tiene similitudes en cuanto a imagen de marca, tamaño del 
establecimiento, producción deslocalizada, técnicas de venta y ubicación estratégica en las calles principales o high streets de los núcleos urbanos.

Desde hace unos años, el incremento de este tipo de establecimientos que pugnan por la centralidad y tienen capacidad para competir en costes y en precio con el comercio tradicional también ha sido objeto de debate en la prensa local sevillana (Barba, 2015; Pereira, 2018), en ocasiones desde una perspectiva nostálgica e incluso tradicionalista. De la misma manera, la retirada de veladores - la terraza de mesas y sillas en el espacio público- de la centenaria confitería La Campana (Ruesga, 2017), en la plaza homónima, generó una amplia polémica que abrió todavía más el debate acerca del rol de estas actividades comerciales en el centro histórico y la posibilidad de la intervención administrativa para evitar su cierre. En esta línea, la Cámara de Comercio ha iniciado un catálogo de "establecimientos emblemáticos" del centro de la ciudad, reconociendo la trayectoria de dieciséis comercios tradicionales que, siguiendo un acuerdo firmado con el Ayuntamiento de Sevilla, podrán recibir bonificaciones fiscales o ayudas para promoción (Parejo, 2018). La estrategia municipal de apoyo a la continuidad de estos negocios responde a las discusiones sobre la pérdida de identidad, la estandarización comercial o la banalización creciente de los paisajes del centro urbano debido a la afluencia turística (Fernández Tabales \& Santos Pavón, 2018). Unas cuestiones que tienen un antecedente en el intento de proteger, por parte de la Junta de Andalucía, la farmacia de la plaza del Salvador a principios de los noventa del siglo XX.

La transformación radical de los paisajes comerciales de zonas urbanas centrales es una tendencia que no es nueva ni exclusiva de Sevilla, sino que se puede hablar de un fenómeno global en el contexto de las políticas urbanas neoliberales. Así, la reciente conceptualización de la gentrificación planetaria (Lees et al., 2016), incluye aquella de carácter comercial o boutificación: la sustitución de unas actividades comerciales más o menos tradicionales o de proximidad por otros establecimientos que normalmente tienen un modelo de negocio diferente y que están destinados a una clientela con otro poder adquisitivo o estilo de vida (Zukin et al., 2009; González, 2018). Estos procesos, generalmente acotados en un espacio determinado, están siendo estudiados en un buen número de casos que varían según la escala y los factores analizados. A escala de ciudad, Nadal Salazar (s.f.) hace un análisis general sobre Madrid y sus distritos a partir de seis tipologías de establecimientos: cafeterías, restaurantes, tiendas de ropa, de alimentación, peluquerías y establecimientos educativos. También a nivel de distrito, el proceso ha sido estudiado en la Ciutat Vella de Barcelona (Pascual Molinas \& Ribera Fumaz, 2009; Cócola Gant, 2015), y, dentro de la misma a escala de barrio, como es el caso del Raval (Moreno, 2010). En esta escala barrial, también destaca el análisis de Romero Renau y Lara Martín (2015) sobre Russa-fa en Valencia y de Díaz Parra y Jover (2019) en la Alameda de Sevilla, que siguen, como en el Raval, un patrón de políticas de revitalización desde finales de los ochenta, seguidas por desplazamiento y sustitución de la población y mejora del medio ambiente urbano tras un amplio ciclo previo de degradación y 
abandono. En esta escala, cómo afecta la peatonalización al tejido comercial es también relevante (Simó López et al., 2018). Otra línea de trabajo en la que se está profundizando apunta a la gentrificación comercial de los mercados de abasto tradicionales, con un alto impacto social y que cabe analizar con facilidad al estar el objeto de estudio muy acotado espacialmente (González \& Waley, 2013; Salinas Arreortúa, 2016; González, 2018). Se trata de un proceso que, como en otros casos a distintas escalas, nunca se produce de forma aislada, sino que se encuentra en relación con procesos más amplios de turistización o gentrificación clásica, como se ha puesto de manifiesto en los mercados de San Miguel de Madrid o la Boquería de Barcelona (Hernández Cordero \& Andreeva Eneva, 2016; García Pérez et al., 2016).

La mayoría de estos estudios, si bien incorporan una perspectiva cultural en tanto que la transformación o la gentrificación comercial suele responder a cambios en los patrones de consumo o en el estilo de vida más allá de los perfiles estrictamente económicos, no incluyen referencias patrimoniales. ¿Qué ocurre cuando los procesos referidos se producen sobre un espacio patrimonial, como un centro histórico? Esta cuestión no se debe abordar desde una única perspectiva, sino que se enriquece si se integran aspectos de las geografías económica y urbana con otros de las geografías crítica y cultural, especialmente la dimensión patrimonial. En este sentido, Prats (2006) afirma que uno de los elementos que más contribuyen a la banalización del espacio urbano es el modelo de negocio de las franquicias y grandes firmas empresariales, que por lo general proliferan a costa del comercio de proximidad. Siguiendo esta hipótesis, el presente trabajo hace un planteamiento de partida consecutivo. En primer lugar, ¿se ha producido un proceso de gentrificación comercial en el centro urbano de Sevilla? ¿existe una pérdida del comercio tradicional? Y si fuera así, ¿por qué? ¿desde cuándo ha ocurrido? ¿cómo afecta el desembarco de franquicias y grandes firmas? En segundo lugar, ¿hay establecimientos comerciales que puedan ser patrimonializables? Y en caso de ser afirmativa la respuesta: ¿cómo habría que articular su protección?

\subsection{Objetivos, metodología y fuentes}

El objetivo del trabajo es determinar si existe, o no, un proceso de gentrificación comercial en el centro urbano e histórico de Sevilla y, de ser así, cual es su temporalidad y alcance. Se trata también de estudiar la relación entre negocios de diferente naturaleza en el mismo espacio urbano: los establecimientos comerciales tradicionales, y las franquicias y grandes firmas surgidas desde la década de los noventa. En relación con ello, además, se abre el debate acerca de la posible banalización del centro histórico de la ciudad y la patrimonialización de determinadas actividades comerciales, así como su articulación con las categorías de protección existente por parte de las administraciones públicas. 
Para alcanzar los objetivos, se realizan cuatro tipos de análisis. En primer lugar, se ha hecho un repaso general sobre la bibliografía acerca de la transformación urbana y la gentrificación comercial en el contexto del capitalismo tardío o posfordista, para generar el debate en torno a estos procesos y vincularlos a la teoría patrimonial actual. En segundo lugar, se ha realizado un repaso de la bibliografía específica sobre Sevilla que incluye informes técnicos y documentos de planificación urbana, comercial y turística, que se complementa con el estudio de variables estadísticas. En tercer lugar, se ha trabajado sobre la llegada de franquicias y grandes firmas a la zona de estudio desde principios del decenio de los noventa, y se ha recopilado información sobre la situación cada doce años, completada con un trabajo de campo realizado a finales de 2017. Finalmente, ese mismo trabajo de campo incluye entrevistas a informantes cualificados entre 2016 y 2018.

El trabajo empírico sobre la geografía comercial se ha basado en la compilación de datos sobre los establecimientos existentes en el espacio urbano de forma triangular delimitado por las plazas Nueva, del Duque de la Victoria y de la Encarnación (Figura 1). El ámbito de estudio comprende 64 plazas, calles, callejones, adarves y pasajes, en su mayoría peatonales desde los ochenta, a excepción de otras que se cerraron al tráfico rodado más tarde (O’Donnell en 2005, plaza Nueva en 2007) y algunas que siguen abiertas al mismo (Méndez Núñez, Laraña o las plazas del Duque y de la Magdalena, que funcionan como terminal de varias líneas de autobuses urbanos). Los datos de principios de los noventa se han extraído de las Páginas Azules de la extinta Compañía Telefónica Nacional de España, que ha paliado la falta de acceso a los datos sobre las licencias de actividad comercial con carácter temporal que en reiteradas ocasiones se solicitaron al Ayuntamiento de Sevilla, sin obtener ninguna respuesta. ${ }^{1}$ Las Páginas Azules consultadas han sido las de los períodos 1992-1993 y 1993-1994. Estas guías, que se compilaban anualmente por calles, ofrecen información precisa sobre la ubicación de residentes y empresas que disponían de una o varias líneas telefónicas. Muchas de estas empresas son establecimientos comerciales, que figuran normalmente con el nombre del negocio e incluso a veces se anuncian como tales ocupando un mayor espacio en la hoja donde figura la calle en la que se localizan-. Así, se realizó una compilación de los comercios en ambos cursos, cruzando los datos para certificar la presencia de las actividades comerciales en 1993, partiendo de la consideración de que en los períodos examinados la mayoría de los negocios disponían de al menos una línea telefónica para comunicarse con los clientes y con los proveedores. La base de datos resultante se ha cotejado con las fuentes bibliográficas existentes sobre comercio tradicional (Pérez Guerra, 1991; Rioja López,

1 Las peticiones se cursaron entre 2015 y 2017, por distintos investigadores y para proyectos con similitudes, el segundo en una cooperación entre departamentos de las Universidades de Sevilla y Pablo de Olavide. El desinterés de las administraciones públicas por facilitar este tipo de datos debería estimular la reflexión sobre el papel que las instituciones en particular y la sociedad en general le otorga a la investigación científica. 
1992; Salas, 2008), con trabajo de hemeroteca sobre publicidad comercial en los periódicos locales y con las fuentes orales en las entrevistas que se han realizado. ${ }^{2}$ Asimismo, los datos han sido confrontados con los de SIGCOMSE, una herramienta de localización geográfica, ya en desuso, sobre las entidades comerciales de Sevilla (Vallejo Villalta \& Márquez Pérez, 2006). Al no tener un campo específico sobre la antigüedad de la actividad económica, no se pudo establecer un motor de búsqueda para comercios tradicionales. Sin embargo, estos datos sí ayudaron al cotejarlos con aquellos sobre las principales franquicias y firmas comerciales en el centro de la ciudad de 2005, extraídos de un trabajo que se publicaría unos años después (Fernández Cuesta \& Fernández Salinas, 2010). Finalmente, a finales de 2017 se recopiló información sobre ambas categorías comerciales: tradicionales y franquicias y grandes firmas. El trabajo de campo se ha complementado con la consulta de las fuentes bibliográficas sobre comercio tradicional anteriormente citadas, y la búsqueda on-line de todos los establecimientos en cuestión. ${ }^{3}$ Esto último ha permitido no solamente clasificarlos siguiendo la hipótesis establecida, sino también por su tipología, resultando una base de datos de más de 700 registros.

En paralelo, se llevaron a cabo diez entrevistas semi-estructuradas con comerciantes del centro histórico, dos de ellas en profundidad y las otras ocho con diferente nivel de extensión, amén de otras tantas conversaciones informales con responsables de otras tiendas. El perfil de los entrevistados es el de propietario o encargado de un comercio tradicional, con al menos treinta años de antigüedad, incluyendo a dos de los más antiguos de la ciudad, con más de un siglo de historia. Los establecimientos en cuestión, de distinta tipología, se encuentran en las calles Tetuán, Velázquez, Sierpes, Cuna, Francos, Chicarreros y las plazas de la Magdalena y El Salvador. Se ha optado por omitir la información de las personas entrevistadas porque algunas mostraron su rechazo a que se hicieran públicas sus opiniones. Además, la confidencialidad sirvió para crear un ambiente más distendido a la hora de responder el cuestionario. Por último, cabe señalar que tanto la Federación de Comerciantes del centro de Sevilla Alcentro, como el Ayuntamiento, no respondieron a las solicitudes que se cursaron para una entrevista.

2 Aunque el objetivo de las entrevistas es otro, se aprovechó para preguntar por los comercios desaparecidos en uno u otro espacio público, dependiendo del entrevistado.

3 La mayoría tienen páginas web, o al menos perfiles en redes sociales (Facebook, Twitter, Instagram) que ha permitido conocer el modelo de negocio. En el caso de las enseñas, también ayudaron las webs especializadas como franquicia.net o infofranquicias.com. Esta información se encuentra detallada en la Cámara de Comercio, que cobra una tarifa por cada establecimiento del que se quiera conocer información. 
Figura 1. Ámbito de estudio

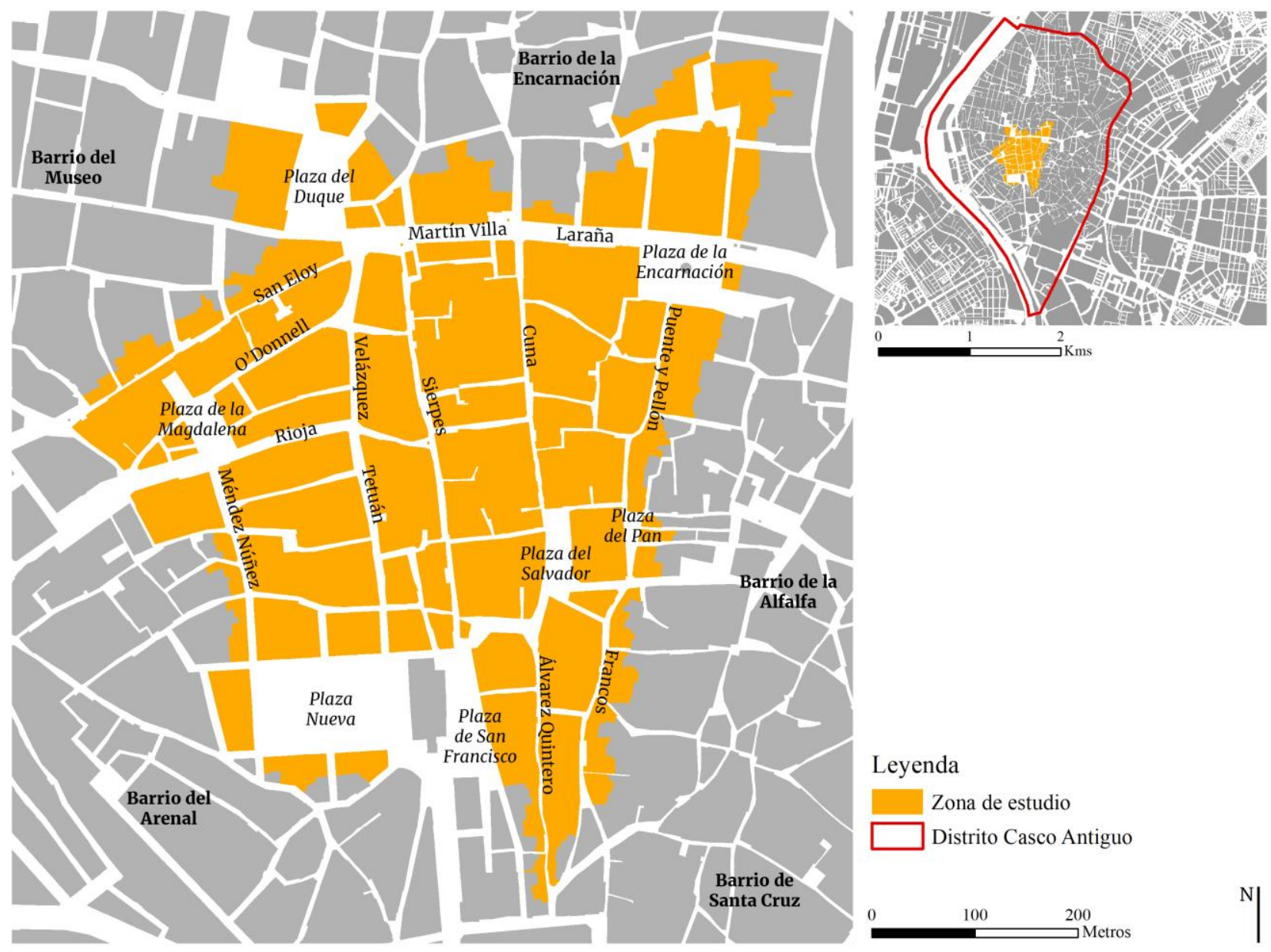

Fuente: elaboración propia a partir de Datos Espaciales de Referencia de Andalucía

\section{La articulación entre capital cultural y gentrificación en los centros históricos}

Desde sus orígenes, las ciudades han sido espacios de intercambios de mercancías. Las ferias y mercados, construidos o efímeros, han estado tradicionalmente en las zonas centrales de las poblaciones. La ciudad siempre ha sido un espacio de consumo, y en la actualidad todavía más, especialmente en Occidente tras la reestructuración económica posfordista. Como resultado, en el contexto posmoderno la cultura se subordina al modo de producción dominante, configurándose como una cultura comercial que absorbe todo tipo de expresiones y que adquiere una dimensión global (Jameson, 1998). Así, en los últimos años se ha prestado una mayor atención al nexo entre capital y cultura, y a cómo está mediatizado por el espacio, siendo esencial la publicación en 1982 del inédito e inacabado Das Passagen-Werk de Walter Benjamin, en el había trabajado de 1927 hasta su muerte en 1940. El filósofo alemán dedicó buena parte de esos escritos al análisis de la trayectoria de los aspectos culturales de las sociedades modernas, estudiando la capacidad del sistema económico capitalista para producir representaciones culturales, o como el mismo 
escribiría: "no se trata de exponer la génesis económica de la cultura, sino la expresión de la economía en su cultura" (1982, p. 462). Si Marx acuñó el concepto de ideología para colmar una laguna y definir la verdad de lo falso que destruye la práctica política (Rancière, 1996), Benjamin utilizó la fantasmagoría para explicar la idea (cultural) que la sociedad capitalista generaba de sí misma, donde el valor de uso de cualquier mercancía se confunde con el valor de cambio hasta el extremo de que el segundo contiene al primero, de la misma forma en la que las relaciones sociales del trabajo que han intervenido en la producción de esa mercancía se difuminan. $\bigcirc$, como Benjamin (1982, p. 680) escribe: "la cualidad fetichista que adquiere la mercancía afecta a la misma sociedad productora de mercancías, no ciertamente como ella es en sí, sino tal como continuamente se imagina a sí misma y cree comprenderse cuando abstrae [sic] del hecho de que precisamente produce mercancías". Estas reflexiones son causa y consecuencia de la observación y el estudio de los pasajes comerciales decimonónicos del París de Haussmann, o la apropiación urbana del centro de la capital francesa por una clase social y la forma arquitectónica que adquiría el consumo en el incipiente desarrollo del capitalismo industrial (Harvey, 2003).

El protagonismo de los pasajes que se construyeron por toda Europa a finales del siglo XIX y durante los primeros años del XX iría perdiendo fuerza a favor de otra tipología arquitectónica con dedicación exclusiva a la actividad comercial y un gran simbolismo: los grandes almacenes. Estos espacios, que surgen del desarrollo de nuevas técnicas de venta y de los avances en los sistemas y materiales constructivos, evolucionan hacia los centros comerciales en el contexto de la ciudad difusa que promueve el urbanismo moderno. La expansión urbana es, siguiendo a Lefebvre (1970), una auténtica revolución en tanto que el espacio ha tomado una nueva dimensión y se comprende de manera dinámica en la reproducción de una estructura de dominación social caracterizada por la cotidianeidad del consumo. En este contexto se impone un modelo cultural que identifica urbanización con modernidad y ambas con consumismo, donde la fantasmagoría de Benjamin se ha convertido en hegemónica. Como apunta Daniels (1992), adquirir un automóvil no es solamente una necesidad generada en el seno de la sociedad consumista, sino que se convierte en un elemento clave en la conformación de lugares porque afecta a la forma, en esencia cultural (significados, prácticas, imágenes) con la que nos relacionamos en y con el espacio. De la misma manera, los lugares que se construyen y reconstruyen son el resultado de tales cambios culturales en la configuración de estas relaciones. Así, Augé (1992) contrapone el concepto de lugar en tanto que espacio "de identidad, relacional e histórico", al de no-lugar, como producto de aquellos procesos. En una línea similar, Zukin (1995) plantea que la cultura y la identidad sirven de canalizador para la acumulación de capital en la ciudad en tanto que se generan plusvalías urbanas de las que este se apropia en los mercados de suelo e inmobiliario. Esto ha ido de la mano de las transformaciones en las pautas de consumo y en el perfil del consumidor (Peck, 2005; Lees et al., 2007), hablándose cada vez más de geografías del consumo. Aquí también son clave los nuevos 
modelos de negocio, la importancia del espectáculo, de la imagen de marca y de las estrategias de publicidad y marketing de las empresas multinacionales en el contexto de la ciudad capitalista (Harvey, 2001).

La gentrificación es el proceso más estudiado en este tipo de ciudad, entendido principalmente en dos planos. Por un lado, como un proceso por el que las clases altas sustituyen a la población previamente residente en determinados barrios - que por lo general han sufrido dejadez e incluso segregación-, aumentando su categoría social, y por otro lado como una estrategia de los principales agentes implicados (bancos, inmobiliarias y administraciones públicas) que se benefician de la plusvalía (o brecha de renta) generada en el mercado. Esta capitalización del incremento de valor se debe a la reinversión en forma de construcción y/o renovación de edificios e infraestructuras de diferente tipo en aquellos barrios (Smith, 1996), que con frecuencia está asociado a la entrada en escena del capital cultural y prácticas de consumo en sus distintas formas. Si bien existen características generales, la gentrificación se desarrolla de distinta manera dependiendo del contexto local en el que se desenvuelve. En los estudios urbanos, especialmente en el mundo anglosajón, se han identificado una serie de olas de gentrificación, ganando importancia desde los noventa el rol de las instituciones públicas por la asunción acrítica de la lógica neoliberal en la gestión de la ciudad (Smith, 2002). En el caso español, este proceso de reformas urbanísticas coincide con la reestructuración económica y del mercado de trabajo y la desregularización del mercado hipotecario (Díaz Parra, 2014; Romero et al., 2015). Con unas décadas de retraso con respecto a los países anglosajones, se vuelve la mirada hacia los centros urbanos otrora abandonados, cuyo carácter histórico y cultural añade un componente simbólico a su revalorización, que marca el ritmo y la profundidad de su rehabilitación y que es capitalizada por los agentes económicos con la imprescindible colaboración de la administración pública. Fundamentado en ese mismo carácter, sobre todo a través del patrimonio, el turismo ha irrumpido en los centros históricos, apropiándose de espacios y contribuyendo a la mercantilización de expresiones culturales dado su fuerte peso en economías urbanas (Benach, 2016; Blanco-Romero et al., 2017). Asimismo, el turismo, que ha adquirido todavía más fuerza tras la crisis, está provocando una nueva ronda de expulsión de población, en la que se combinan procesos de gentrificación y turistización (Jover \& Díaz Parra, 2019).

La pérdida de población de los centros históricos y su sustitución por otra de mayor poder adquisitivo con pautas de consumo más agresivas y/o selectas, sea residente o turista, unido a la configuración de parte de estos centros como espacios de consumo, se retroalimenta con procesos de gentrificación comercial. Así, esta no se interpreta exclusivamente como la terciarización de un espacio urbano determinado, sino también como una sustitución de actividades comerciales con una componente de identidad barrial y de vecindad, que han satisfecho necesidades de la población durante décadas, por otras que no tienen esta característica. Siguiendo a Cócola Gant 
(2015), se trata de un desplazamiento indirecto, en tanto que añade presión al tejido social en el que se produce, afectando a la cotidianeidad del sector urbano en cuestión. La consecuencia es la pérdida de la memoria urbana al descomponerse los lugares en la conceptualización de Augé (1992), esto es, como ámbitos de encuentro y de vida en común. A diferencia de los no-lugares, como son los centros comerciales modernos, los espacios comerciales urbanos de los centros históricos no nacieron con este destino consumista, sino de proveer las necesidades de los vecinos; y a pesar de la disolución total o parcial de sus mimbres identitarios como comunidad por los distintos procesos urbanos que se solapan, su potencia como espacios relacionales y sobre todo históricos sigue estando presente. Esta disolución es el resultado de la modificación diaria que sufren desde la perspectiva del consumo, donde se entrelazan nuevos estilos de vida, modas, artículos y patrones de compra -especialmente por Internet- con distinta formas de ocio y turismo; y de la producción, que se deja notar en la espectacularización y la elitización del espacio, con aumento de rentas inmobiliarias y de la especulación, lo que condiciona la forma en la que se reconfigura física y culturalmente los lugares en los que se desarrolla la actividad comercial. Esta articulación de la economía capitalista con la cultura establece necesidades comunes -y en la mayoría de casos artificiales - a lo largo y ancho del planeta, lo que tiende a la estandarización del producto y a la homogeneización. Ahora bien, la paradoja se halla en que para que la acumulación de capital pueda seguir funcionando, es necesaria cierta diferenciación cultural, de ahí que la autenticidad urbana sea cada vez más una parte integrante de la experiencia de consumo (Harvey, 2001), cuestión que puede ser explotada con más facilidad en los centros históricos debido a su trayectoria histórica y a su potencia identitaria.

En este contexto emerge la teoría patrimonial, especialmente las tesis que fomentan una perspectiva crítica, poniendo el foco sobre cómo a un objeto se le atribuye la categoría de patrimonio. Siguiendo su origen estatal, los procesos de patrimonialización son proyectados y dirigidos por las instituciones, si bien en las últimas décadas son cada vez más permeables a iniciativas ciudadanas. En los contextos occidentales, el valor cultural del patrimonio está construido socialmente, por lo que la administración pública, aunque es la representante de aquella sociedad y tiene la potestad para declararlo oficialmente e implementar políticas para su preservación, no tiene el monopolio para reconocer e interpretar el patrimonio. Este concepto ha comenzado a ensancharse y resignificarse a raíz de una mayor sensibilidad social, reclamando una mayor participación en el proceso y apareciendo - con todas sus contradicciones políticas y culturales- diferentes formas de percibirlo y considerarlo por parte de comunidades locales (Sánchez Carretero, 2012; Jover Báez y Almisas Cruz, 2015). En este ámbito cabe enmarcar el debate sobre los mercados de abastos como bienes culturales, incitado por el creciente reconocimiento del patrimonio intangible (Silverman, 2015). Este tipo de mercado tradicional no tiene, por lo general, argumentos patrimoniales materiales, o no tiene porqué tenerlos, pues su valor reside en su condición de nodo 
en torno al que se estructura un barrio o sector urbano, las relaciones sociales que en él se generan e incluso las formas de consumo local que se preservan, que en ocasiones ponen en contacto directo a productores y consumidores. Así, lo que se considera patrimonio es la trayectoria temporal y el carácter cultural de la actividad comercial en ese mercado en concreto, o incluso en un establecimiento particular. Aquí el asunto clave es responder a la pregunta: ¿de dónde proviene ese reconocimiento como patrimonio? A grandes rasgos, cabe señalar dos respuestas. La primera y menos frecuente es que la comunidad local sienta como propia una actividad o un espacio comercial. Este sentir se puede reflejar mediante artículos de prensa, como se ha señalado en la introducción, aunque no tiene por qué expresarse únicamente por este medio, ni apoyarse en los mismos argumentos. La segunda respuesta apunta a la autenticidad urbana, por el que los establecimientos entendidos como patrimonio, como el propio espacio comercial en un centro histórico, se convierten en un atractivo más para la experiencia de consumo (Figura 2), lo que ha llevado por ejemplo a estudiar la incidencia turística en la normativa sobre paisaje urbano (Fernández Tabales y Santos Pavón, 2018). La conversión en capital cultural de la actividad comercial supone poner el foco en su valor simbólico, en cierto sentido reescalando la mercantilización, es decir, convirtiendo en mercancía el aspecto cultural de una actividad que en sí se centra en vender mercancías. Al mismo tiempo, se añade complejidad al debate en torno a la teoría patrimonial en cuanto al dinamismo del objeto que se protege, a las razones que se exhiben y a las formas de articulación de dicha protección.

\section{Figura 2. Cartel publicitario en el centro de Sevilla}

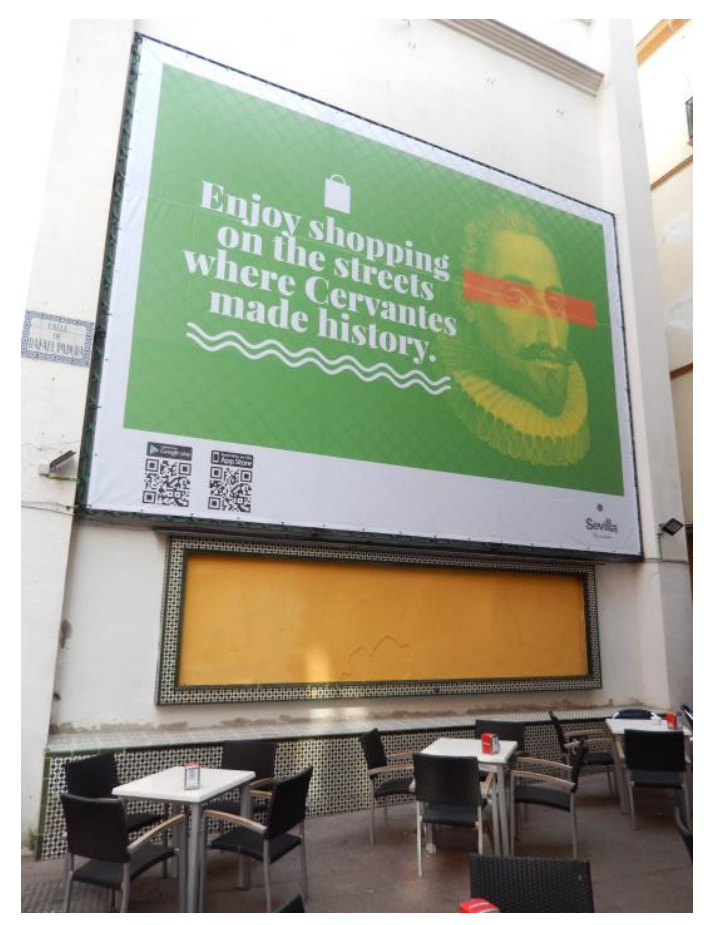

Fuente: el autor, febrero de 2016. Retrieved from Geophotopedia:

$$
\text { https://www.flickr.com/photos/jaimejover/46565902812/ }
$$




\section{El centro de Sevilla como espacio comercial e histórico}

\subsection{Contexto del comercio en Sevilla y su centro histórico}

La evolución de la actividad comercial en Sevilla en los últimos años tiene varias lecturas, dependiendo de los datos disponibles. Según el Impuesto de Actividades Económicas para la serie disponible, entre 1992 y 2015, las actividades comerciales -incluyendo la hostelería (restaurantes y alojamientos) - han sabido resistir a la crisis, e incluso han crecido. A pesar del estancamiento en los períodos 1993-1995 y 2007-2012, el número de las actividades comerciales ha pasado de 17625 en 1992 a 26267 en 2015 (datos de la Consejería de Economía, Innovación y Ciencia de la Junta de Andalucía). Sin embargo, ambas cifras constituyen el 55 \% y el 38 \% del total de las actividades económicas respectivamente. A principios de los noventa, el comercio constituía el sector económico más importante de la ciudad. En 2015 seguía siendo la principal actividad, pero su importancia se había reducido, en gran medida por el peso relativo que han ido ganando otros servicios terciarios, como los financieros o de energía y agua. Esta situación se corresponde con la que se desprende de los datos de los establecimientos por actividad económica según el CNAE09, disponibles entre 2007 y 2017. En este período, los establecimientos comerciales se han reducido en un millar (de 15735 en 2007 a 14675 en 2017), mientras que los establecimientos hosteleros compensan la pérdida, creciendo en una cifra muy similar, especialmente en los últimos años: de 3985 en 2012 a 4951 en 2017 (datos del Instituto de Estadística y Cartografía de Andalucía). En el cómputo global, el peso relativo de estos establecimientos en el período se mantiene en torno al $34 \%$. Los datos reflejan la progresiva terciarización de la economía sevillana desde los noventa, y dentro de la misma, la pérdida de peso del sector estrictamente comercial en detrimento de la especialización en otros nichos económicos, como la hostelería. El peso relativo del comercio también debe ponerse en relación con las nuevas formas de negocio electrónico o e-commerce en el caso de los establecimientos, y de forma general con la dinámica de crecimiento metropolitano (Vahí Serrano y Hurtado Rodríguez, 2017). De hecho, en el contexto actual la venta en grandes superficies sigue creciendo, a excepción de los productos alimenticios, como muestran los datos del índice de ventas en grandes superficies de Andalucía (Instituto de Estadística \& Cartografía de Andalucía, 2019).

Respecto del análisis del centro histórico de Sevilla, siguiendo con lo ya comentado, cabe señalar su carácter comercial, que se remonta siglos atrás especialmente en el ámbito de estudio (Figura 1). Dentro del mismo, y en perspectiva histórica, se distinguen dos zonas. Por un lado, se encuentra la aglomeración minorista en el entorno de la iglesia del Salvador, que describiera Luis Cernuda y que, como señala Marín de Terán (1980), pierde importancia desde los sesenta coincidiendo con el aterrizaje de los grandes almacenes en su entorno. De este primitivo zoco salen cuatro largas calles en dirección N-S, dos hacia el sur: Francos y Álvarez Quintero, no por casualidad conocida 
antiguamente como de Mercaderes; y otras dos hacia el norte: Cuna y Lineros-Puente y Pellón. Las cuatro calles ganan intensidad comercial en las proximidades de las plazas del Salvador y del Pan, que actúan como nodos comerciales y estructuradores del espacio público. Las pequeñas vías que unen estas calles en dirección E-O también preservan una intensa actividad, al igual que la continuación de estas hacia el Este (plazas de la Pescadería y de la Alfalfa) y al Oeste, hacia las plazas Nueva y San Francisco. Por otro lado, los ejes Sierpes y Tetuán-Velázquez representan el cambio en la lógica comercial que se produjo en la ciudad en el siglo XX. La pérdida de pulso urbano de este espacio desde mediados de siglo, con una progresiva despoblación que se traduce en el abandono y destrucción de parte del tejido edilicio, se compensa con la terciarización (Marín de Terán, 1980). El papel del turismo ya era un elemento clave, concentrado en el entorno de Santa Cruz desde la apertura de la avenida de la Constitución en el primer cuarto del siglo XX, configurada como una gran vía donde se asentaron funciones administrativas y comerciales (Díaz Parra, 2016). Sin embargo, el principal hito que ilustra la terciarización se produce en los sesenta, con la implantación de grandes almacenes en las plazas del Duque y de la Magdalena. Así, la centralidad comercial se extiende hacia el Oeste de la plaza del Salvador, alcanzando a los mencionados ejes y consolidándose en calles adyacentes como O’Donnell, San Eloy, Rioja o San Pablo. El espacio resultante, cuya actividad empresarial fue estudiada por Vega Benayas (1989), aglutina el mayor número de comercios y soporta la mayor intensidad de tal función en el centro de Sevilla en la actualidad ${ }^{4}$, que se ve reforzada por el fuerte peso que ha adquirido el turismo urbano, impulsando procesos de turistización que se entrelazan con los de gentrificación (Jover \& Díaz Parra, 2019).

La mayoría de este espacio comercial histórico se encuentra delimitado, dentro del distrito casco antiguo de Sevilla, en el barrio de la Alfalfa, con ramificaciones hacia los sectores Museo, Arenal y Encarnación. La complejidad del análisis trae causa de la carencia de los datos disponibles a escala inframunicipal, siquiera recopilados por la administración local. Significativamente, el censo de 2011 no incorporó información acerca de los locales comerciales, cuestión que sí hizo su antecesor y que ofrece una radiografía de la situación a principios del siglo XXI. El censo de 2001 contabilizó 8146 locales activos de un total de 9480 registrados, teniendo en consideración que no se distinguen entre oficinas, talleres, establecimientos comerciales y hoteleros. La estadística supone un 85,93 \% de actividad empresarial en el centro histórico, muy superior a la de otras zonas, en un espacio que apenas concentraba el 7,7 \% de la población total (en la actualidad, el centro histórico ha ganado población y representa el 8,24 \%, datos del Padrón Municipal). De todos los locales

4 Cabe reseñar la existencia de otros ejes comerciales históricos, significativamente el que conforman las calles Regina y Feria, y que todavía tiene mucho peso en la ciudad, donde cada jueves se celebra el último mercadillo ambulante del centro de Sevilla. Las dinámicas urbanas cambiantes de esta zona que afectan al tejido comercial, como la del entorno de la plaza de la Alfalfa, tienen sus particularidades y podrían tratarse en futuros trabajos. 
activos, más de la mitad se dedican a una actividad comercial: 4452. Por zonas se observa una fuerte concentración, ya que la Alfalfa tiene el 26,19\% de los locales comerciales activos, seguida del Museo con el 25,18 \%, y a mayor distancia el Arenal (8,94 \%) y la Encarnación (8,67 \%). En el otro extremo se sitúan los barrios de San Lorenzo (2,9\%) y San Vicente $(1,17 \%)$, con escasa dinámica comercial. Además, el censo contiene datos en un nivel más de desagregación: de los 4452 locales comerciales, 2077 ocupan con su actividad un solo inmueble, mientras que 2348 están en inmuebles con actividad compartida, normalmente viviendas. Entre los primeros se distinguen alojamientos turísticos (hoteles) o inmuebles para actividades comerciales de forma exclusiva, y se concentran en el corazón de la ciudad, sobre todo en los barrios del Museo (42,37\% del total del centro histórico) y la Alfalfa (31,44 \%), siendo prácticamente insignificante en San Vicente o San Gil. Entre los segundos se encuentran los edificios que compaginan un uso residencial y terciario, que está más extendido por toda la ciudad histórica, aunque son más comunes en la Alfalfa (21,85 \%), el Arenal (11,5\%) y la Encarnación $(9,97 \%)$.

Además de los datos del censo, a finales de los noventa Vahí Serrano (1998) observa la convivencia del comercio tradicional con las franquicias y las grandes marcas, en expansión en ese momento, en el centro y en otros puntos de Sevilla y su área metropolitana (Nervión-Los Arcos, Los Remedios, Aljarafe). En el global de Andalucía las franquicias representaban entonces el $5 \%$ del total de la actividad comercial (Junta de Andalucía, 1998, como se citó en Vahí Serrano, 1998). Los últimos años han visto aumentar este tipo de negocio de forma exponencial. En toda España, el número de enseñas se ha doblado entre 2001 y 2016, mientras que la facturación ha crecido un 42,3 \%, a pesar de la crisis (Asociación Española de Franquiciadores, 2017). Andalucía es de las regiones con un mayor volumen de negocio, destacando su implantación en Sevilla. Según los últimos informes, estas son más comunes en los centros comerciales, sobre todo en los sectores de la moda y la restauración, aunque también destacan en zonas del centro (Geniz, 2018b). La ubicación céntrica de este tipo de negocios ha repercutido en los últimos años en el precio de los locales comerciales, teniendo un comportamiento desigual según las calles, como se observa en la Tabla 1.

De esta estadística destaca la polarización entre distintas vías. En general, se observa el descenso del precio medio de alquiler de los locales comerciales en un buen número de calles, en algunos casos muy pronunciados como en Rioja, O'Donnell y Cuna. Las razones generales del descenso cabe buscarlas en una mayor disponibilidad de locales en estas calles, por la crisis económica y la destrucción del tejido comercial que supuso, los nuevos modelos de negocio mencionados y, también, debido al fin de los arrendamientos de renta antigua tras la prórroga de veinte años que había establecido la Ley de Arrendamientos Urbanos en 1994. Por el contrario, los ejes Sierpes y Tetuán-Velázquez, a pesar de haber sufrido un ligero descenso durante los años de la crisis, han incrementado los precios de sus locales comerciales recientemente, dejando entrever el peso que 
tienen ambas calles en la distribución comercial en el centro de Sevilla, especialmente el segundo. Se trata de unas diferencias muy amplias entre las distintas vías en un espacio muy pequeño, en las que algunas de ellas son bocacalles de otras.

Tabla 1. Precio medio de alquiler ( $€ / \mathrm{m}^{2}$ mes) en locales comerciales según calles

\begin{tabular}{|l|c|c|c|c|c|}
\hline & 2009 & 2012 & 2015 & 2018 & Variación 09-18 \\
\hline Cuna & 36,4 & $s / d$ & 26,8 & 24,5 & $-32,7 \%$ \\
\hline O'Donnell & 37,3 & $s / d$ & 24,5 & 25 & $-33 \%$ \\
\hline Plaza Nueva & 87,5 & $s / d$ & 76,5 & 75 & $-14,3 \%$ \\
\hline Rioja & 107,5 & 95,5 & 63 & 64,5 & $-40 \%$ \\
\hline Sagasta & 58,5 & $s / d$ & 44 & 46,5 & $-20,5 \%$ \\
\hline Sierpes & 70,6 & 62,5 & 74 & 71,5 & $2,1 \%$ \\
\hline Tetuán/Velázquez & 125 & 111,5 & 134 & 150 & $20 \%$ \\
\hline
\end{tabular}

Fuente: Inerzia (2011, 2015 y 2018)

\section{2 ¿El comercio como patrimonio? Notas sobre la relación entre la planificación urbana, turística y patrimonial.}

En la actualidad no existe ningún comercio tradicional reconocido como bien de interés cultural, si bien hubo un intento frustrado a finales de 1989, cuando la Delegación Provincial de Cultura de la Junta de Andalucía en Sevilla promovió la inscripción de la Farmacia del Salvador, una de las más antiguas de las que se tenía constancia en la ciudad (Rioja López, 1992). A principios de 1990, conforme a los informes preceptivos, se incoa el expediente para declarar la farmacia como monumento; sin embargo, nunca se termina de resolver, quizá porque durante la tramitación del procedimiento administrativo había aparecido la Ley del Patrimonio Histórico Andaluz de 1991, que articulaba una nueva categoría de catalogación de menor entidad que el bien de interés cultural, y dentro de esta, otras figuras diferentes a la de monumento, como el lugar de interés etnológico. Sea como fuere, en 1993 se tiene constancia de que la farmacia está siendo desalojada, y aunque la Dirección General de Bienes Culturales de la Junta de Andalucía se esfuerza por preservar unos bienes que ya habían sido incoados, no puede evitar el desenlace (Jover Báez, 2017). La desaparición de este comercio tradicional, cuyo valor residía en su apariencia exterior y en los bienes muebles del interior, supuso el único intento conocido de declarar individualmente una actividad económica. Tras esta experiencia negativa, los órganos competentes de la Consejería de Cultura de la Junta de Andalucía no se han vuelto a interesar por esta forma de reconocimiento institucional de ningún comercio tradicional.

Una afirmación similar se puede hacer sobre el Ayuntamiento de Sevilla, teniendo en consideración que también tiene una potestad de protección conforme al planeamiento. El catálogo urbanístico del 
Plan General de Ordenación Urbana de 2006 no incluye ninguna referencia específica a la protección del comercio local; en cambio, sí se hace un reconocimiento indirecto cuando se tratan los usos terciarios en el centro histórico: "la oportunidad del planeamiento debe encaminarse al fomento del comercio especializado y singular. En concreto, declarar como localización prioritaria la correspondiente a los ejes y sectores tradicionales" (Ayuntamiento de Sevilla, 2006; Memoria de Ordenación, XII, p. 54). Es decir, no se concreta una protección de establecimientos comerciales, sino de las funciones que se concentran en determinados espacios públicos. De esta manera, el Plan General cataloga ejes y nodos urbanos con marcado carácter comercial, como las secuencias Alameda-Sierpes/Tetuán ( $\left.n^{\circ} 1\right)$ o Álvarez Quintero-Plaza Europa ( $\left.n^{\circ} 2\right)$; o los enclaves de La Campana ( $n^{\circ}$ 16) o la plaza del Pan ( $\left.n^{\circ} 24\right)$. El carácter de tales espacios está configurado por la continuidad temporal de la actividad comercial, tanto que se conforma como "un hecho patrimonial de carácter testimonial respecto a la estructura profunda de la ciudad histórica en determinadas etapas" (Ayuntamiento de Sevilla, 2006). En esta línea, y antes de la aprobación del plan general, el Ayuntamiento había conseguido más de dos millones de euros de fondos FEDER que, junto a otro millón aportado por el consistorio, se invirtieron en la Operación Restauro del "Proyecto de renovación del Paisaje Urbano en el Conjunto Histórico de Sevilla". Entre 2000 y 2006, el Ayuntamiento suscribió convenios con más de 120 comercios tradicionales de las calles Francos, Álvarez Quintero, Cuna o Puente y Pellón para sufragar hasta el 80 \% de las obras de rehabilitación y adecuación de locales y señales publicitarias (Salas, 2008).

Esta política municipal se extendió a comercios tradicionales de barrios como Feria o Triana. Aquí se observa como el concepto de ciudad histórica es el que proporciona el marco para identificar como patrimonio algunos establecimientos comerciales. El centro histórico de Sevilla está declarado como bien de interés cultural con la categoría de conjunto histórico, lo que, en virtud de la legislación existente, supone el engranaje entre la planificación urbanística y la política cultural. La primera se realiza a través del Plan General, mientras que la segunda la ejecuta el Plan Especial de Protección del Conjunto Histórico, una herramienta de planificación urbanística adaptada a las necesidades de conservación del patrimonio. La particularidad de esta planificación está en su naturaleza y el procedimiento de redacción de los planes. En primer lugar, el Plan Especial de Protección no está subordinado al Plan General, sino que funcionan en paralelo y, en el ámbito concreto de los conjuntos históricos andaluces, ha de existir cierto nivel de articulación (Barrero Rodríguez, 2006). En segundo lugar, si bien estos planes también los redacta el consistorio, la competencia en materia de cultura es de la administración autonómica, por lo que requieren la aprobación del departamento correspondiente de la Junta de Andalucía. Hasta que eso no sucede de forma definitiva, la Comisión Provincial de Patrimonio Histórico ejerce la facultad de aprobar o denegar las intervenciones en los sectores sin plan especial, como las relativas al espacio público o a la rehabilitación o sustitución de un inmueble, especialmente si está catalogado. En el caso de 
Sevilla, el conjunto histórico actual es una ampliación de 1990, para la que el consistorio aprueba en 1994 un documento de avance, esto es, unas directrices generales sobre la zona, y debido a su amplio tamaño se divide en 27 sectores -y algunos sucesivamente en dos, tres o cuatro subsectores-. A finales de los noventa se inicia la política de planificación de la ciudad histórica, dándose preferencia a la aprobación de planes especiales en ámbitos extramuros y en el norte del distrito casco antiguo, fuera de la zona comercial que se estudia. De hecho, como explica Jover Báez (2017), dicha zona es la que concentra un mayor número de licencias de obras de reforma entre 1987 y 2007, debido a la intensidad y dinamismo de la actividad económica que soporta. Los planes especiales que regulan el devenir patrimonial en el ámbito comercial del centro histórico de Sevilla comienzan a desarrollarse en la primera década del siglo XXI (Ayuntamiento de Sevilla 2007), y comienzan a aprobarse en la siguiente, con una particularidad: la protección de establecimientos comerciales tradicionales de forma individualizada (Ayuntamiento de Sevilla, 2011). Aunque la justificación se encuentra en su interés etnológico, al ubicarse todos en edificios catalogados, tal criterio se asocia a la materialidad del inmueble, por lo que no existen fichas o documentos exclusivos que traten los valores culturales de los comercios.

En cualquier caso, la protección patrimonial del comercio tradicional en el ámbito de estudio no solamente es compleja en lo que respecta a su aplicación práctica, ni es la única regulación vigente en un área que en los últimos años está soportando un incremento de la función turística. Este hecho precisamente justifica la declaración de zona de gran afluencia turística a finales de 2014, recientemente renovada, flexibilizando los horarios de apertura en varios fines de semana, durante la Semana Santa y el resto de la primavera. La zona casa aproximadamente con el reconocimiento como centro comercial abierto, que se consiguió en 2013 con base en la normativa andaluza, dirigida a apoyar y consolidar el comercio minorista de una zona urbana determinada mediante acciones de promoción e incentivos económicos de origen autonómico. Para ello, la solicitud partió de la Federación de Comerciantes del centro de Sevilla "Alcentro", que está compuesta por más de 250 empresas y que genera sus propias guías comerciales, campañas de publicidad e imagen, amén de ofrecer servicios de consultoría y asesoramiento a sus asociados. ${ }^{5}$ No obstante, ninguna de esas acciones desde el nacimiento de la asociación en 2007 se han centrado en el reconocimiento patrimonial, a diferencia de la propuesta iniciada en 2018 por la Cámara de Comercio, como se mencionó más arriba.

5 Para más información, visitar su página web: https://www.sevillashopping.org/ 


\section{La transformación comercial del centro urbano de Sevilla (1993-2017)}

\subsection{La evolución de las franquicias y grandes firmas}

En el casi cuarto de siglo que abarca el período de estudio, los datos reflejan un importante aumento de las enseñas y grandes firmas. En 1993, se contabilizan 16 establecimientos franquiciados y 52 pertenecientes a grandes firmas, observándose diferencias espaciales entre ambas categorías. Las franquicias, fundamentalmente de ropa y calzado, se distribuyen entre la plaza Nueva y la calle Sierpes, con algunas ramificaciones en la calle Tetuán, la Campana y el entorno de la iglesia del Salvador. En cambio, las grandes firmas se reparten con mayor homogeneidad. Esto se debe, por una parte, a la alta presencia y dispersión de entidades bancarias, si bien el mayor número se concentra en la plaza de San Francisco, donde está situada la sede del Banco de España. Por otra parte, la razón se encuentra en la dispersión de los grandes almacenes nacionales y locales: El Corte Inglés en la plaza del Duque, Galerías Preciados en la Magdalena, Almacenes Vilima en Puente y Pellón o Almacenes Peyré en Francos. Así, en líneas generales, cabe decir que en esta zona de la ciudad existía una presencia comercial importante de firmas nacionales e internacionales, si bien no era el modelo de negocio mayoritario todavía.

Doce años después, a principios del siglo XXI, la situación ha cambiado. Las franquicias se han multiplicado por cinco, hasta 81, mientras que las grandes firmas se mantienen en cifras similares, un total de 49. De estas últimas, un cuarto corresponde a entidades bancarias, cuyo número se ha reducido tras la reestructuración del sistema bancario español desde finales de los noventa. Algo similar ocurrió en el campo de los grandes almacenes a los que se hacía referencia, con el cierre de aquellas firmas locales y la adquisición por parte de El Corte Inglés de establecimientos en las plazas de la Magdalena y del Duque, aumentando su presencia en el ámbito estudiado. También aparecen en tendencia ascendente los grupos Inditex y Cortefiel, con múltiples tiendas de distintas marcas que copan las calles principales. Así, en aquel momento, las grandes firmas se concentran entre las plazas Nueva y del Duque, salvo la tienda Lefties del grupo Inditex en la calle Puente y Pellón. Este establecimiento, que vende prendas de menor calidad o de otras temporadas por un precio reducido, da cuenta de la división espacial en el centro urbano de Sevilla. Las calles del sector oriental del ámbito de estudio, representadas por los ejes Tetúan-Velázquez y Sierpes, consolidan su posición como calles comerciales señeras, donde las grandes firmas generan sinergias con las franquicias. El aumento de estas, sobre todo en tales vías y sus adyacentes como O’Donnell o Rioja, ilustra este proceso. Por su parte, los ejes Cuna y Puente y Pellón-Lineros en la zona occidental del espacio estudiado continúan albergando establecimientos tradicionales o nuevas firmas locales e incluso regionales y nacionales, con precios más asequibles, normalmente para otro perfil de consumidor. Sin embargo, hay excepciones, como la proliferación de franquicias de trajes de novia y artículos para bodas en la calle Cuna y la plaza del Pan, instalados para aprovechar las 
sinergias con los establecimientos locales de la misma tipología que ya existían ahí. Un proceso similar ocurre con las franquicias de moda como Calvin Klein o Armani, que se abren en una calle con poca penetración de marcas internacionales como es Francos, donde estaba Peyré, que ya había cerrado en 2005. Estas franquicias de moda, que venden productos de ropa, complementos y calzado, predominan en el tejido comercial, aunque también existen joyerías, ópticas o restaurantes, destacando las cadenas multinacionales de comida rápida.

Más de una década después, con una profunda crisis económica por medio, la expansión de estos modelos de negocio en el centro de Sevilla ha alcanzado una nueva dimensión. En 2017 se contabilizan 135 enseñas, un 67 \% más de las que había en 2005, a los que cabe sumar 93 locales de grandes firmas, un $89 \%$ de crecimiento con respecto a 2005. Dentro de esta categoría, los establecimientos bancarios y tiendas de moda de las principales corporaciones españolas representan más de la mitad del total, mientras que el resto lo componen firmas multinacionales con tiendas propias, entre las que destacan las de telefonía y las de belleza o estética. Como se observa en la figura 3, la concentración de estos establecimientos se ha profundizado en el eje Tetuán-Velázquez y Sierpes, aumentando también su presencia en las calles O’Donnell y Rioja o en las plazas Nueva, Campana y de San Francisco, en este último caso siguiendo la tendencia de años anteriores, con un número significativo de oficinas bancarias. Las franquicias también han aumentado en estas calles, y han penetrado con fuerza en otras tradicionalmente ocupadas por firmas locales, como en San Eloy, Cuna y, en menor medida, Martín Villa-Laraña o Puente y Pellón. En este proceso destaca la inauguración del Metropol Parasol en la plaza de la Encarnación en 2011, en cuyo espacio comercial en parte de la planta baja -la que no corresponde al mercado de abastos- se localizan franquicias hosteleras. Con respecto a la tipología de enseñas, es interesante que continúa el predominio de los locales especializados en productos de moda en todo el ámbito de estudio. Sin embargo, otros dos datos destacan: el crecimiento del número de franquicias españolas, algunas incluso andaluzas, especialmente en la restauración -donde sobresale el grupo Restalia- y la diversificación de tipologías. Bajo el modelo de franquicias existen en la actualidad establecimientos de belleza, de electrónica y telefonía, de productos de alimentación gourmet, de souvenirs o casas de apuestas, y han irrumpido con fuerza las cadenas de supermercados, con mayoría de productos precocinados.

En definitiva, cabe afirmar que los ejes comerciales centrales se han convertido en espacios mayoritariamente ocupados por comercios no tradicionales, lo que ha tenido reflejo en el ascenso de los precios del metro cuadrado antes comentado. Así, entre franquicias y grandes firmas suman el 47,2 \% de los locales comerciales contabilizados en la calle Sierpes, y hasta un 52,6 \% y 59 \% en la plaza Nueva y el eje Tetuán-Velázquez respectivamente. Al mismo tiempo, el espacio que ocupan estas tipologías comerciales se ha ampliado hacia otras zonas normalmente destinadas a comercio tradicional y/o de proximidad, como la arteria entre la Catedral y la plaza de la 
Encarnación a través de las calles Francos, Lineros y Puente y Pellón. No obstante, esta expansión es todavía tentativa, puesto que la tipología comercial dominante sigue siendo otra.

Figura 3. Evolución de las franquicias y grandes firmas en el centro de Sevilla (1993, 2005 y 2017)
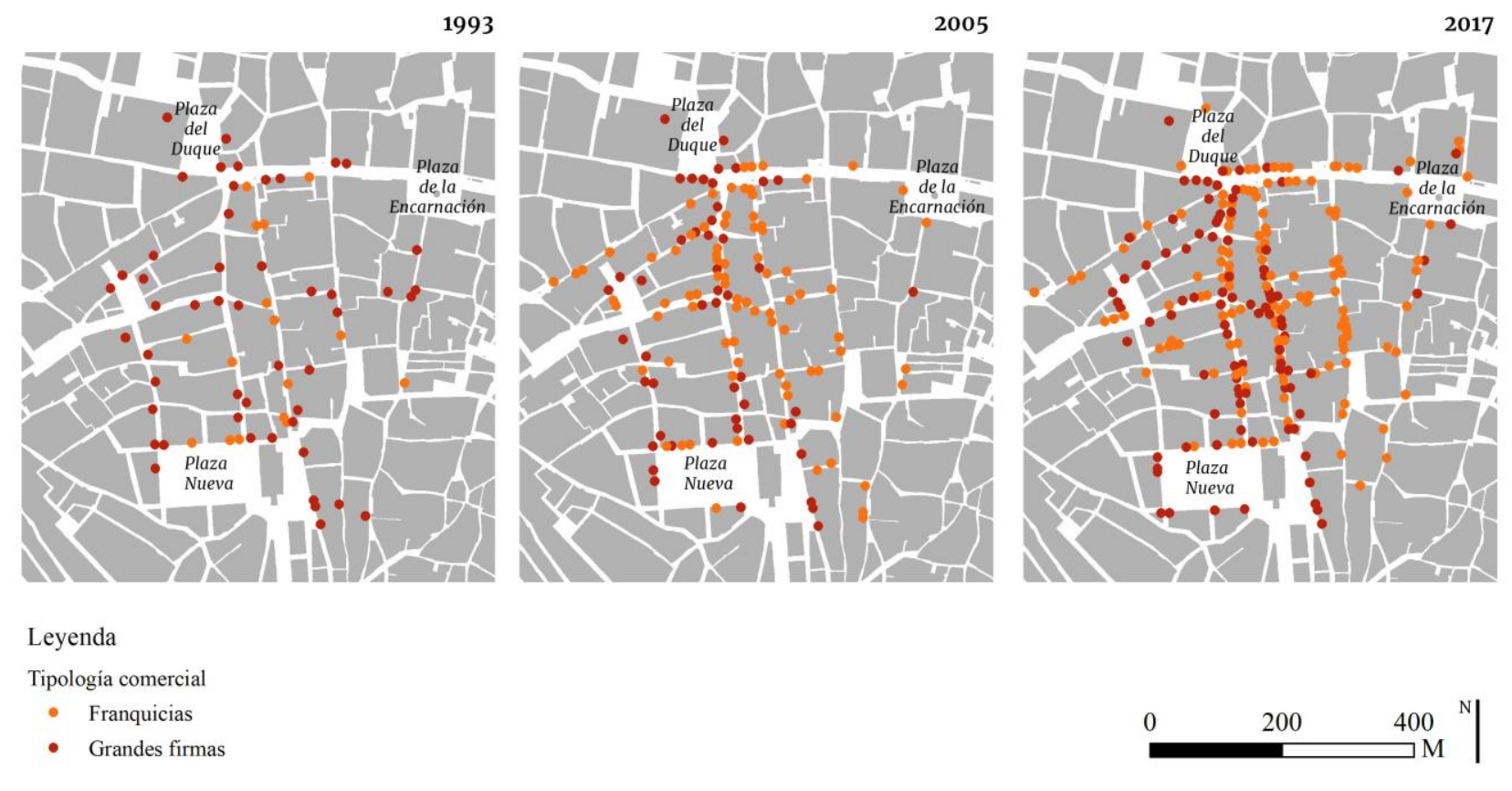

Fuente: elaboración propia a partir de páginas azules,

bibliografía, fuentes orales y trabajo de campo

\subsection{El comercio tradicional que resiste. Análisis de establecimientos y miradas}

En paralelo al incremento de franquicias y grandes firmas, el comercio tradicional se ha ido reduciendo, como ya se ha referido. Las referencias de las que se disponen han permitido mapear el estado actual (Figura 4), contabilizando hasta 136 comercios, en su mayoría familiares y con un solo establecimiento, si bien existen excepciones de empresas arraigadas que cuentan con diversos puntos de venta. Sin perjuicio de lo expuesto, cabe hacer una diferenciación entre el comercio tradicional de tres áreas con dinámicas distintas. En primer lugar, en las calles principales persisten una serie de establecimientos muy especializados y que disponen del local en propiedad, como sombrererías Maquedano en Sierpes o confección Noguel en Tetuán. Muy especializadas son también las tiendas de Foronda y Díaz entre Sierpes y Tetuán, que venden mantones, mantillas y abanicos. A este tipo de comercio tradicional especializado y con más de un punto de venta también responde bolsos Casal o las tiendas de bisutería de Elena Bernal. A todo ello cabe sumar un buen número de locales hosteleros tradicionales, tanto cafeterías (La Campana, Ochoa, Catunambú, etcétera) como restaurantes (Laredo, Mesón Castellano, La Viuda, etcétera), que se localizan principalmente entre las calles General Polavieja y Albareda. Por su parte, en las plazas del Duque y de la Magdalena, así como en la calle Laraña, no se ha contabilizado ningún comercio 
de estas características, y muy pocos en calles aledañas como Martín Villa, O’Donnell o San Eloy, donde la dinámica actual está haciendo desaparecer las tipologías tradicionales. Como botón de muestra, la conversión de una empresa familiar como el Grupo San Eloy en franquiciadora, o la joyería Sotero, perjudicada por el fin de la renta antigua, que ha conseguido permanecer, de momento, litigando en los tribunales (Parejo, 2016).

Figura 4. Localización de comercios tradicionales en el centro de Sevilla

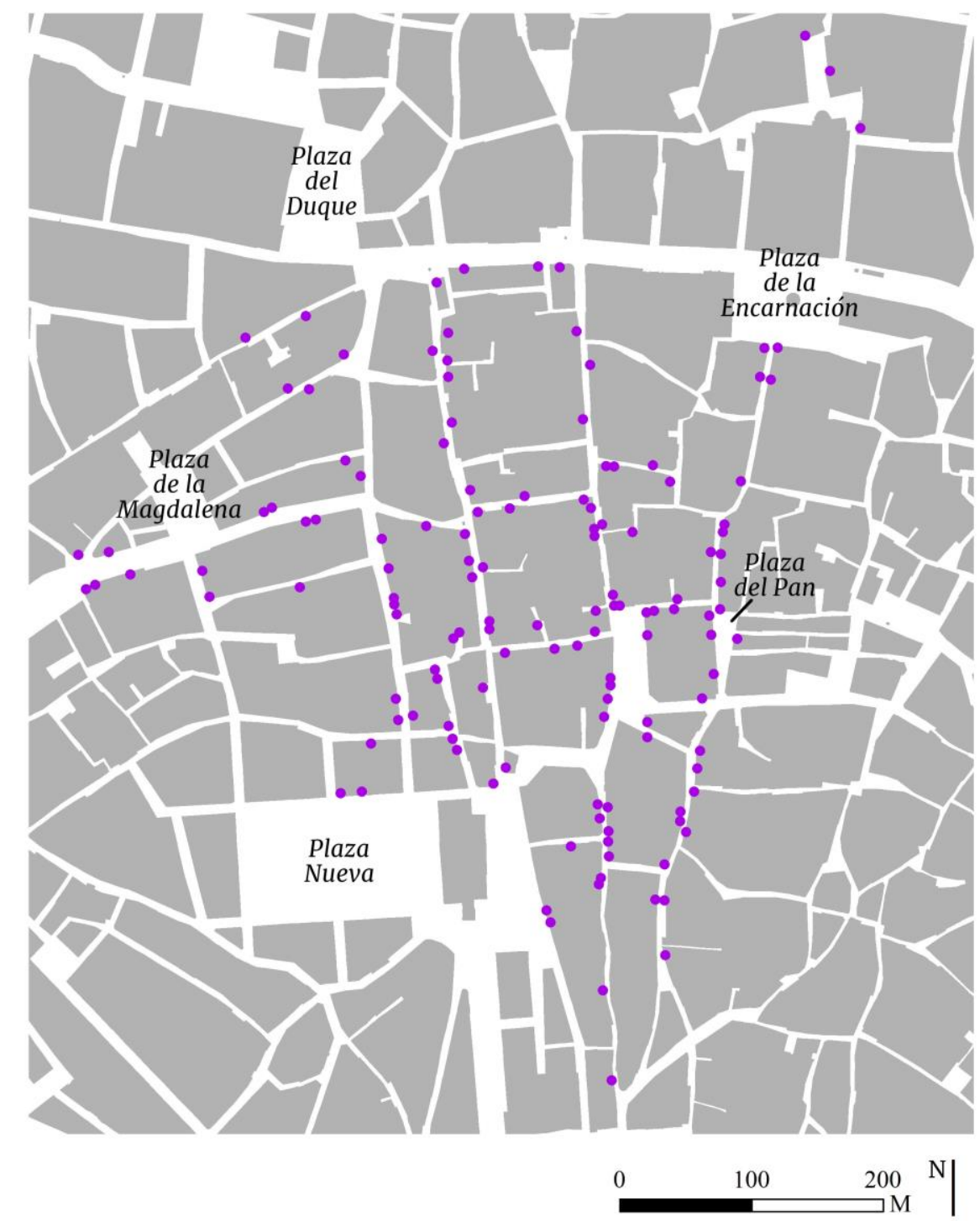

Fuente: elaboración propia a partir de páginas azules, bibliografía, fuentes orales y trabajo de campo

En segundo lugar, es preciso referirnos a las zonas hacia donde se está extendiendo la tipología de franquicias y grandes firmas, que ha sido objeto de fuertes transformaciones: las calles Cuna y Puente y Pellón, así como el entorno de la plaza de la Encarnación, que tras la remodelación de principios de siglo, perdió su condición de terminal de líneas de autobuses urbanos. A pesar de una potencial menor afluencia de público, en estas vías han resistido un buen número de locales 
relacionados con la confección de ropa (Galerías Madrid, Oro Blanco) y los complementos (guarnicionería López, mercería Peña). Una mención especial merece la tienda de ultramarinos Casa Lucas en Puente y Pellón, que es la última que queda en todo el ámbito de estudio. En el entorno inmediato de la plaza de la Encarnación, la fuerte transformación tras la inauguración del macro proyecto ha hecho que solo queden los cafés Alcázares, La Centuria y Spala, y dos establecimientos especializados -tapicería y cuchillería respectivamente- en la desembocadura de la calle Regina. En los últimos años, en esta plaza se han perdido tiendas de muebles en mimbre y de decoración y soluciones para el hogar, y se han reformado por completo establecimientos hosteleros, como el bar La Unión. En tercer y último lugar, se encuentran aquellas vías donde el comercio tradicional es todavía significativo y se combina con firmas nacionales e internacionales, como en Sagasta, Cerrajería o San Pablo. En esta línea, destacan aquellos espacios donde todavía se produce cierta concentración gremial, como el caso de las zapaterías en la calle Córdoba; las tiendas de antigüedades en la calle Acetres, los bares típicos en la plaza del Salvador -en los soportales-; o las mercerías, corseterías y tiendas de objetos religiosos en Francos y Álvarez Quintero. En estas dos últimas vías, junto a Lineros y la plaza del Pan, pervive con especial fuerza un significativo número de establecimientos tradicionales, entre ellos almacenes de tejidos y confección (Velasco, Canales, Algarín Hermanos), joyerías (Serrano Navarro, Bernal, Chauvin) y talleres de relojería que ni siquiera rotulan un nombre comercial. Del mismo modo, cabe destacar la tienda de fotografía Santana o la de incienso Fiances, en una de esas covachas que describía Luis Cernuda en la plaza del Pan.

En cuanto a las miradas, todos los comerciantes entrevistados son, como mínimo, de segunda generación, y en algunos casos los establecimientos - en los que se ha conservado la distribución antigua y en ocasiones también el mobiliario- están abiertos mucho antes de que su familia se hiciera cargo del negocio. Las entrevistas discurren por cuatro líneas temáticas y relacionadas entre sí: relativas al carácter del establecimiento y el entorno; a la clientela y potenciales cambios percibidos; a las transformaciones del tejido comercial local y a la existencia de valores culturales en sus establecimientos y posibles formas de conservarlos.

En primer lugar, sobre el carácter de los establecimientos, una pequeña parte de los entrevistados considera que tienen el carácter propio una tienda de proximidad, identificando el centro como barrio, aunque la mayoría reconoce que traspasa sus fronteras en cuanto a la afluencia de clientes -que vienen desde otras partes de la ciudad e incluso de municipios metropolitanos-. Sin embargo, ante la pregunta de qué consideran el centro, con frecuencia delimitan las principales vías comerciales objeto de estudio, así como los barrios del Arenal, Alfalfa o Santa Cruz, pocas veces haciendo referencia al global del distrito casco antiguo. En segundo lugar, en referencia a la clientela y los cambios percibidos, las respuestas varían dependiendo del tipo de establecimiento. Para las tiendas de confección, de lotería, venta de entradas o menaje del hogar, el público sigue 
siendo el mismo por el nivel de especialización o las características del producto que ofrecen, "de alta calidad a un buen precio" según varios entrevistados. Un caso particular está representado por una tienda de complementos, de más de un siglo de antigüedad, que trabaja por encargo y recibe pedidos de otras partes de España, de Europa e incluso de Estados Unidos. En otros casos, sí se ha notado un cambio sustancial en el tipo de cliente en los últimos años. Sin haber perdido la fidelidad del público local, reconocen que también venden a turistas con mayor asiduidad. No obstante, en estos casos aseguran que no solamente han cambiado los clientes, sino también los productos y los gustos.

Lo expuesto está en relación con las transformaciones en el tejido comercial. Existe unanimidad entre los entrevistados en la revolución que ha sufrido su actividad con la irrupción de Internet y en concreto de las plataformas de venta on-line, tanto por la reducción -en distinto nivel de intensidad- de las ventas, como por los cambios en los modelos de consumo. En este sentido, pocos establecimientos han optado por tener una página web, y han seguido funcionando con base en las redes locales creadas. Los cambios en los modelos de consumo también se trasladan a la geografía comercial del centro, donde varios entrevistados relacionan dichos cambios con la proliferación de grandes firmas y franquicias en los años recientes, el consecuente incremento de los precios de los locales comerciales y la pérdida de comercios tradicionales. De hecho, un par de comerciantes destacan que si el local donde se sitúa el negocio no se dispone en propiedad, es muy difícil mantenerse, y recuerdan cómo el fin de la prórroga de la Ley de Arrendamientos Urbanos causó la desaparición de muchos de ellos. Sin embargo, apuntan a más razones para este particular, como las diferentes crisis económicas - la última es un asunto reiterado en todas las entrevistas-, así como aspectos familiares, por ejemplo, la jubilación de una persona y la falta de motivación en el negocio por sus herederos. Al respecto, algunos comerciantes manifiestan su confianza para seguir existiendo en su posición de comercio de proximidad, con un trato diferencial, cercano, y productos de alta especialización; mientras que otros se resisten e identifican los cambios con el devenir del mercado, llegando incluso a afirmar en un par de casos que el comercio tradicional terminará desapareciendo.

Por último, en relación a estas transformaciones, se preguntó por la existencia o no de valores culturales en sus comercios, así como la necesidad de protegerlos y las formas de realizarlo en caso afirmativo. En líneas generales, todos los comerciantes creen que sus establecimientos tienen aquellos valores, apuntando a la tipología tradicional, a cuestiones sentimentales y a las formas de relación con el cliente o la identidad que otorgan al entorno en el que se encuentran -esto último particularmente señalado por los entrevistados en las calles Sierpes y Velázquez, precisamente allí donde la transformación ha sido más intensa, como se ha visto-. Ahora bien, también reconocen que en muchos casos es la dinámica del mercado, por lo que si el cliente no aprecia el trato recibido, el tipo, precio y calidad del producto o directamente prefiere comprar en grandes 
superficies o por Internet, poco pueden hacer por preservar tales valores. En cualquier caso, la gran mayoría de entrevistados piensa que algún tipo de reconocimiento podría implementarse, como mínimo a través de una placa que refiera los años que llevan abiertos. Pocos conocen la catalogación urbanística, y son recelosos ante cualquier iniciativa municipal. Sí están de acuerdo por lo general en que una forma para fomentar que sus establecimientos no desaparezcan podría ser a través de ayudas, como las indirectas en forma de bonificación de impuestos. Aunque ninguno piensa que tales ayudas lleguen a producirse alguna vez.

\section{Conclusiones y discusión}

Los datos de los que disponemos apuntan a que, por las diferentes razones ya enumeradas, el comercio tradicional está en regresión en el centro histórico de Sevilla, mientras que las franquicias y grandes firmas se expanden con distinto grado de intensidad según el espacio. La sustitución o gentrificación de comercio local por otro modelo de negocio de escala nacional o internacional ha sido progresiva en las principales vías del ámbito estudiado (plaza Nueva, Campana, calles Sierpes, Tetuán y Velázquez) desde, al menos, el primer decenio del siglo XXI. El comercio tradicional que ha resistido tiene unas condiciones muy particulares en términos de propiedad del local, especialización del producto y una clientela fidelizada. No obstante, el número de establecimientos de este tipo sigue reduciéndose en detrimento de grandes firmas y franquicias, que colonizan cada vez más calles en el ámbito de estudio, contribuyendo a banalizar el tejido comercial. Eso sí, todavía persiste una jerarquía entre distintas vías y la situación cambia radicalmente en cuestión de metros. En las calles adyacentes a los ejes principales, se produce cierta superposición entre tipologías comerciales, aunque con tendencia dispar. En calles al oeste (Méndez Núñez, Rioja, O’Donnell, San Eloy), la transformación ha sido más fuerte desde principios de siglo, si bien la crisis parece haber reducido esta dinámica. Hacia el este, en Cuna, Puente y Pellón, Francos o Álvarez Quintero, persiste cierta concentración gremial y el comercio tradicional resiste e incluso se retroalimenta con algunas franquicias y grandes firmas que aparecen en el paisaje urbano. En el conjunto del ámbito, la especialización turística de la ciudad se deja notar, con más marcas multinacionales y también establecimientos cada vez más orientados a visitantes, como las cadenas de supermercados o las tiendas de souvenirs. Esta lógica, junto a la condición peatonal de casi la totalidad de las calles estudiadas, también coadyuva a la consolidación y promoción de los centros comerciales abiertos, donde el comercio tradicional teje alianzas con franquicias y grandes firmas. Si bien las sinergias pueden ser positivas para la permanencia de esta tipología, también existen amenazas, puesto que estos establecimientos no están en pie de igualdad en cuanto a imagen de marca, gasto en publicidad o diversidad del producto, y en un contexto de fuerte competencia puede conllevar su desaparición. 
Esta sustitución comercial es precisamente lo que ha espoleado el debate patrimonial. Al respecto cabe hacer dos reflexiones, sobre la situación actual y las perspectivas futuras. En primer lugar, el comercio tradicional no se ha protegido activamente. La única fórmula prevista ha sido a través del planeamiento, donde los intereses etnológicos que podrían tener potencialmente estos establecimientos se han subordinado a un catálogo de edificios, por lo que no debe sorprender que los planes especiales no dispongan de ninguna fórmula concreta para asegurar la conservación y promoción de aquellos intereses. En segundo lugar, e incluso antes de esto, conviene debatir sobre la pertinencia del comercio tradicional como patrimonio. No deja de ser contradictorio que el valor cultural -esencialmente un valor de uso o disfrute- que estos establecimientos pueden albergar emerja de una práctica de consumo, es decir, de otorgar representatividad social a una actividad que se fundamenta en el intercambio de mercancías. Esto es especialmente relevante sabiendo que la mercantilización de la vida cotidiana a través del consumo es uno de los pilares de procesos urbanos como la gentrificación o la creciente turistización, que tanta incidencia han tenido y tienen en aspectos inmateriales de los centros históricos. Pero quizá precisamente por eso la protección del comercio tradicional es relevante. El argumento a favor del reconocimiento de estos como patrimonio se centra en la identidad que por su historia condensan los establecimientos, vinculado al mobiliario tradicional o a la imagen exterior, que además se asocia a una actividad mercantil que nació en un contexto no consumista, sino de provisión de bienes para la vida diaria. Aquí enraíza todo lo que representan como experiencia comercial: necesidades más específicas de la población, productos locales, trato personal y cercano, y en definitiva el comercio como lugar de socialización. En este sentido, el comercio tradicional sería patrimonio, y su protección podría articularse desde la administración municipal, a través del planeamiento pero de forma individualizada y precisa, o desde la autonómica, donde cabría explorar la posibilidad de redactar planes directores sobre el comercio tradicional de un espacio en concreto (barrio o ciudad), siempre en coordinación con otros departamentos que pudieran garantizar su pervivencia, por ejemplo a través de bonificaciones fiscales. El debate está abierto y estas reflexiones pretenden ayudar en una tarea que, en última instancia, debe fundamentarse en el consenso social.

Agradecimientos: Agradezco a Ana Avila su ayuda durante el trabajo de campo y los contactos con algunos de los entrevistados, y a Víctor Fernández Salinas e Ismael Vallejo Villalta por la cesión altruista de la información de sus trabajos que ha facilitado esta investigación. También me gustaría dar las gracias a Julio Sánchez Moreno y a Luis Jover, así como a tres revisores anónimos, por sus comentarios y sugerencias sobre una primera versión de este texto. Por supuesto, solo yo soy responsable del contenido final.

Declaración responsable: El autor declara que no existe ningún conflicto de interés con relación a la publicación de este artículo. 


\section{Bibliografía}

Alonso Logroño, M.P., López-Escolano, C,Arranz-López, A., \& Pueyo Campos, A. (2017). Ubicación de las franquicias y grandes cadenas comerciales después de la gran recesión. El caso de la ciudad de Zaragoza. Ería, XXXVII(3), 335-352.

Asociación Española de Franquicias (2017). Informe: la franquicia en España. Retrieved from http://www.franquiciadores.com/wp-content/uploads/2017/03/Informe-AEF-La-Franquicia-en-

\section{Espa\%C3\%B1a-2017-1.pdf}

Augé, M. (1998) [1992]. Los no lugares. Espacios del anonimato. Barcelona: Gedisa.

Ayuntamiento de Sevilla (2006). Plan General de Ordenación Urbana. Retrieved from https://www.urbanismosevilla.org/areas/planeamiento-desa-urb/pgou-vigente-1

Ayuntamiento de Sevilla (2007). Avance del Plan Especial de Protección del Conjunto Histórico de Sevilla. Sector 8 "Encarnación-Magdalena". Retrieved from https://sig.urbanismosevilla.org/PGOU2006_Des.aspx

Ayuntamiento de Sevilla (2011). Plan Especial de Protección del subsector 8.3 "El Duque-El Salvador". Retrieved from https://sig.urbanismosevilla.org/PGOU2006_Des.aspx

Barba, E. (2015, November 29). Franquicias y cadenas toman el centro de Sevilla. ABC Sevilla. Retrieved from https://sevilla.abc.es/sevilla/sevi-franquicias-y-cadenas-toman-centro-sevilla201511291056_noticia.html

Barrero Rodríguez, C. (2006). La ordenación urbanística de los Conjuntos Históricos. Madrid: lustel.

Benach, N. (2016). ¿Ciudades en el mapa o en la guía turística? Venta de la ciudad y sentido del lugar. Revista CIDOB d'Afers Internacionals, 113, 89-105.

Benjamin, W. (2005) [1982]. Libro de los pasajes. Madrid: Akal.

Blanco-Romero, A., Blázquez-Salom, M., \& Mínguez, C. (2017). Claves de la reestructuración turística de la ciudad. En Actas del XXV Congreso de la Asociación de Geógrafos Españoles (pp. 1516-1524). Madrid: Asociación de Geógrafos Españoles.

Burgos, A. (2015, December 17). Uclés cierra. ABC Sevilla, p. 15.

Cernuda, L. (2014) [1942]. Ocnos. Sevilla: Renacimiento.

Cócola Gant, A. (2015). Tourism and commercial gentrification. In The Ideal City: between myth and reality. Urbino (Italy), RC21 International Conference. Retrieved from https://www.rc21.org/en/wp-content/uploads/2014/12/E4-C\%C3\%B3cola-Gant.pdf 
Correal, F. (2017, 12 mayo). Cien metros pueden más que cien años. Diario de Sevilla. Retrieved from https://www. diariodesevilla.es/sevilla/Cien-metros-pueden-cien-anos_0_1135086999.html

Daniels, S. (1992). Place and the geographical imagination. Geography, 77(4), 310-322.

Díaz Parra, I. (2014). La gentrificación, un regreso a la ciudad de la intervención urbanística. Boletín de la Asociación de Geógrafos Españoles, 64, 321-340. http://dx.doi.org/10.21138/bage. 1700

Díaz Parra, I. (2016). Sevilla 1929-1992. La producción de una mercancía. In Grupo de Estudios Antropológicos La Corrala (coord.), Cartografía de la ciudad capitalista (pp. 195-218). Madrid: Traficantes de Sueños.

Díaz Parra, I., \& Jover, J. (2019) Enclaves urbanos de éxito. Transformación urbanística, gentrificación y turismo en la Alameda de Hércules de Sevilla. In J. Gasca-Zamora (Ed.), Capital Inmobiliario. Producción y transgresión del espacio social en la ciudad neoliberal (pp. 337-357). México D.F.: Universidad Nacional Autónoma de México.

Fernández Cuesta, G., \& Fernández Salinas, V. (2010). El comercio y el turismo. In G. Fernández Cuesta \& F. Quirós Linares (dir.), Atlas Temático de España. Tomo IV: Minería, Energía, Industria, Comercio y Turismo (pp. 299-389). Oviedo: Nobel.

Fernández Tabales, A., \& Santos Pavón, E. (2018). La difícil convivencia entre paisaje urbano y turismo: clasificación de conflictos y propuestas de regulación a partir del análisis comparativo de normativas locales. Boletín de la Asociación de Geógrafos Españoles, 78, 180-211. http://dx.doi.org/10.21138/bage. 2715

Fernández Salinas, V., \& Silva Pérez, R. (2015). Criterios para la identificación y selección de paisajes españoles susceptibles de ser incluidos en la Lista del Patrimonio Mundial de la Unesco. Boletín de la Asociación de Geógrafos Españoles, 68, 253-278. http://dx.doi.org/10.21138/bage. 1861

García Pérez, E., Rodríguez Sebastián, A., \& Maiello, V. (2016). La transformación de los mercados municipales de Madrid: nuevas fronteras de la gentrificación comercial. Alteridades, $26(51), 43-56$.

Geniz, D. (2018a, February 9). Cierra tras 47 años Sabina, la tienda de bisutería de Tetuán. Diario de Sevilla. Retrieved from https://www.diariodesevilla.es/sevilla/cierre-tienda-bisuteria-TetuanSabina_0_1308769300.html

Geniz, D. (2018b, December 12). Las franquicias colonizan el comercio. Diario de Sevilla. Retrieved from https://www.diariodesevilla.es/sevilla/franquicias-colonizan-

comercio_0_1216978818.html 
González, S. (Ed.) (2018). Contested Cities, Contested Markets: Gentrification and Urban Justice in Retail Spaces. Abingdon: Routledge.

González, S., \& Waley, P. (2013). Traditional retail markets: the new gentrification frontier? Antipode, 45(4), 965-983.

Harvey, D. (2001). Espacios del capital. Madrid: Akal.

Harvey, D. (2003). París, capital de la modernidad. Madrid: Akal.

Hernández Cordero, A., \& Andreeva Eneva, S. (2016). ¿Mercados, museos o malls? La gentrificación de los mercados municipales en Barcelona y Madrid. EntreDiversidades. Revista de Ciencias Sociales y Humanidades, 6, 143-173.

Inerzia (2011, 2015 \& 2018). Informes del Mercado de Locales Comerciales de Sevilla. Retrieved from http://www.inerzia.com/informes-de-mercado.html

Instituto de Estadística y Cartografía de Andalucía (2019). Las ventas a precios constantes en las grandes superficies aumentaron un $1,8 \%$ en noviembre. Retrieved from http://www.juntadeandalucia.es/institutodeestadisticaycartografia/ivgs/notaprensa.htm

Jameson, F. (1998). The cultural turn. Selected writings on the postmodern, 1983-1998. New York: Verso.

Jover Báez, J. (2017). Volviendo al centro histórico. La recuperación diferencial del patrimonio y su supeditación a dinámicas urbanísticas: el caso de Sevilla (Doctoral dissertation, Universidad de Sevilla, Spain). Retrieved from https://idus.us.es/xmlui/handle/11441/63968

Jover Báez, J., \& Almisas Cruz, S. (2015). Recuperando espacios y resignificando el concepto patrimonio desde los movimientos sociales. El caso del CSOA La Higuera (Cádiz, Andalucía). Documents d'Anàlisi Geogràfica, 61(1), 91-112.

Jover Báez, J., \& Díaz Parra, I. (2019). Gentrification, transnational gentrification and touristification in Seville, Spain. Urban Studies. http://dx.doi.org/10.1177/0042098019857585

Lees, L., Slater, T., \& Wyly, E. (2007). Gentrification. Nueva York: Routledge.

Lees, L., Shin, H. B., \& López-Morales, E. (2016). Planetary Gentrification. Cambridge: Polity Press.

Lefebvre, H. (1972) [1970]. La revolución urbana. Madrid: Alianza.

Marín de Terán, L. (1980). Sevilla: centro urbano y barriadas. Sevilla: Ayuntamiento de Sevilla.

Morales Padrón, F. (1996). Luis de Peraza. Historia de Sevilla. Sevilla: Asociación de Amigos del Libro Antiguo. 
Moreno, S. (2010). Actividades comerciales, centralidad y gentrification. In S. Martínez Rigol (Ed.), La cuestión del centro, el centro en cuestión (pp. 199-213). Lleida: Milenio.

Nadal Salazar, L. (s.f.). Esa magdalena huele a muffin. Estudio de la gentrificación en Madrid. Retrieved from http://www.formato.es/gentrificacion/

Navarro Antolín, C. (2018, December 18). Cierra el negocio de cerámica 'Martian', casi 40 años en Sierpes. Diario de Sevilla. Retrieved from https://www.diariodesevilla.es/sevilla/Cierranegocio-ceramica-Martian-Sierpes_0_1310269390.html

Parejo, J. (2016, August 4). Otra sentencia avala a un comercio de renta antigua a seguir en su local. Diario de Sevilla. Retrieved from https://www. diariodesevilla.es/sevilla/sentencia-comercioantigua-seguir-local_0_1050795240.html

Parejo, J. (2018, December 10). El Ayuntamiento dará incentivos fiscales a los establecimientos emblemáticos. Diario de Sevilla. Retrieved from https://www. diariodesevilla.es/sevilla/Ayuntamiento-dara-incentivos-fiscales-establecimientosemblematicos_0_1308169572.html

Pascual Molinas, N., \& Ribera Fumaz, R. (2009). Retail gentrification in Ciutat Vella, Barcelona. In L. Porter \& K. Shaw (Eds.), Whose urban renaissance (pp. 180-190). London: Routledge.

Peck, J. (2005). Struggling with the creative class. International Journal of Urban and Regional Research, 29(4), 740-770.

Pereira, M.J. (2018, August 31). Las tiendas de Sevilla que se llevaron la crisis, internet y la falta de relevo generacional. ABC Sevilla. Retrieved from https://sevilla.abc.es/sevilla/sevi-tiendas-sevillallevaron-crisis-internet-y-falta-relevo-generacional-201808311152_noticia.html

Pérez Guerra, A. (1991). Comercios sevillanos que hacen historia. Sevilla: Rodríguez Castillejo.

Prats, L. (2006). La mercantilización del patrimonio: entre la economía turística y las representaciones identitarias. PH Boletín, 58, 72-80.

Rancière, J. (2012) [1996]. El desacuerdo. Buenos Aires: Nueva Visión.

Rioja López, C. (1992). La tienda tradicional sevillana. Sevilla: Consejería de Obras Públicas \& Transportes.

Romero, J., Brandis, D., \& Melo, C. (2015). El giro neoliberal de las políticas para la ciudad en España. Balance a partir de los ejemplos de Madrid y Valencia. Boletín de la Asociación de Geógrafos Españoles, 69, 369-386. http://dx.doi.org/10.21138/bage. 1901

Romero Moragas, C., Jover, J., Berdonces, L., Navarro, C., Gómez, D., \& Galera, V. (2015). Ciudadanía contra el rascacielos Pelli-Cajasol en Sevilla. In Actas del II Congreso Internacional de 
Buenas Prácticas en Patrimonio Mundial (pp. 481-507). Menorca: Consell Insular de Menorca \& Universidad Complutense de Madrid.

Romero Renau, L. del, \& Lara Martín, L. (2015). De barrio-problema a barrio de moda: gentrificación comercial en Russa-fa, el "soho" valenciano. Anales de Geografía, 35(1), 187-212. Salas, N. (2008). Mercurio sevillano. Sevilla: Fundación Cámara Oficial de Comercio e Industria de Sevilla.

Salinas Arreortúa, L. (2016). Transformación de mercados municipales de Madrid. De espacio de consumo a espacio de esparcimiento. Revista INVI, 86(31), 179-201.

Sánchez Carretero, C. (2012). Hacia una antropología del conflicto aplicada al patrimonio. In B. Santamarina (coord). Geopolíticas patrimoniales (pp. 195-210). València: Germania.

Sánchez-Moliní, L. (2018, 1 noviembre). Comercios difuntos. Diario de Sevilla. Retrieved from https://www.diariodesevilla.es/opinion/articulos/Comercios-difuntos_0_1296470371.html

Silverman, H. (2015). Heritage and authenticity. In E. Waterton \& S. Watson (Eds.), The Palgrave Handbook of Contemporary Heritage Research (pp. 69-88). Hampshire: Palgrave Macmillan.

Simó López, M., Casellas, A., \& Avellaneda, P. (2018). Comercio minorista y peatonalización: evolución y adaptación en la ciudad costera de Malgrat de Mar (Barcelona). Anales de Geografía, $38(1), 219-238$.

Smith, N. (2012) [1996]. La nueva frontera urbana. Ciudad revanchista y gentrificación. Madrid: Traficantes de Sueños.

Smith, N. (2002). New globalism, new urbanism: gentrification as global urban strategy. Antipode, $34(3), 427-450$.

Troitiño Vinuesa, M. A., \& Troitiño Torralba, L. (2018). Visión territorial del patrimonio y sostenibilidad del turismo. Boletín de la Asociación de Geógrafos Españoles, 78, 212-244. http://dx.doi.org/10.21138/bage.2716

Vahí Serrano, A. (1998). Franquicia comercial y ciudad en los años 90: Sevilla y su área metropolitana. In Actas del IV Coloquio de Geografía Urbana y VI Coloquio de Geografía del Turismo, Ocio y Recreación (pp. 326-335). Las Palmas de Gran Canaria: Asociación de Geógrafos Españoles.

Vahí Serrano, A., \& Hurtado Rodríguez, C. (2017). Centros comerciales y dinámica urbana en el contexto metropolitan español. Estudio de casos. Investigaciones Geográficas, 68, 27-45.

Vallejo Villalta, I., \& Márquez Pérez, J. (2006): SIGCOMSE: un sistema de información geográfica aplicado al comercio en la ciudad de Sevilla. GeoFocus, 6, 28-38. 
Vega Benayas, S. de la (1989). El centro urbano de Sevilla en los albores de los ochenta. Sevilla: Diputación Provincial.

Zukin, S. (1995). The cultures of cities. Oxford: Blackwell.

Zukin, S., Trujillo, V., Frase, P., Jackson, D., Recuber, T., \& Walker, A. (2009). New retail capital and neighborhood change: boutiques and gentrification in New York City. City \& Community, 8(1), $47-64$. 